\title{
Influence of infiltration on soil erosion in green infrastructures
}

\author{
Janarul Shaikh"*, Sudheer Kumar Yamsani², Manash Jyoti Bora ${ }^{3}$, Sanjeet Sahoo', \\ Sreedeep Sekharan ${ }^{4}$, Ravi Ranjan Rakesh ${ }^{5}$ \\ ${ }^{1}$ C.V Raman Global University, Bhubaneswar, Odisha, India \\ ${ }^{2}$ National Institute of Technology, Warangal, Telangana, India \\ ${ }^{3}$ Indian Institute of Technology Guwahati, Assam, India \\ ${ }^{4}$ Indian Institute of Technology Guwahati, Assam, India \\ ${ }^{5}$ Bhabha Atomic Research Centre, Mumbai, Maharashtra, India
}

Article Details: Received: 2021-01-04｜Ａccepted:2021-03-04｜Ａvailable online: 2021-05-31

cc) $\left(\begin{array}{l}\mathrm{BY} \\ \mathrm{BC}\end{array}\right.$

Rainwater-induced erosion in green geotechnical infrastructures such as a multilayered landfill cover system (MLCS) is a severe concern in the current era. Although vegetation is a proven measure to control erosion in the MLCS, there are other factors such as infiltration rate which influence the control of the phenomenon. Most of the existing studies are limited to understand influence of vegetation on erosion control or infiltration rate alone. In this study, an attempt is made to incorporate infiltration measurements alongside vegetation cover to understand erosion in surface layer of the MLCS. For this purpose, a pilot MLCS was constructed, and erosion of its surface soil was temporally evaluated through soil loss depth of eroded cover surface under the influence of natural as well as simulated rainfall conditions. Alongside erosion, the amount of vegetated cover was evaluated through photographic image analyses and infiltration rate was measured by mini disk infiltrometer. From the observed results, it is understood that soil erosion and infiltration rate depict a contrasting behaviour with growing vegetation. Antecedent moisture contents were observed to show greater influence on such erosion behaviour which was observed during the testing period. Such studies may be helpful to researchers and practicing engineers for understanding performance of various green geotechnical infrastructures and scheduling the maintenance services to increase the longevity of their layered soil systems.

Keywords: erosion, vegetation, infiltration, surface soil, multilayered landfill cover system

\section{Introduction}

Rainfall-induced erosion is one of the most important concerns involved with layered soil system of different geotechnical green infrastructures such as a multilayered landfill cover system (MLCS) (Xue et al., 2016). It needs prime attention particularly if environmental influence of uncovered waste is considered (Shaikh et al., 2019a; Yamsani et al., 2017). Shaikh et al. (2021) investigated seepage characteristics of MLCSs under an extreme ponding condition through detailed laboratory column tests and finite-element seepage analyses. Their study suggested that erosion can be controlled by managing surface-water runoff, minimizing seepage flow, and selecting a surface layer material that can withstand anticipated erosive stresses. Swope (1975) studied 24 landfill cover systems in the USA and found that 33\% had slight erosion, $40 \%$ had moderate erosion, and more than
$20 \%$ had severe erosion. In the United States of America, most landfill cover system top decks are designed to have an inclination in the range of 2 to $5 \%$, after accounting for settlement, to promote surface runoff (Nyhan, 2005). Based on the literature, slopes flatter than $2 \%$ may cause water to be ponded on the surface (Anderson \& Stormont, 1997). Slopes greater than 5\% likely promote erosion, unless preventive measures are taken (Gross et al., 2002). Excessive erosion or slope instability rises as the cover system inclination increases (Morris \& Stormont, 1998). The soil surface should be uniformly graded and sloped at about 3\% to prevent ponding of rainwater (Koerner \& Daniel, 1997). According to Sherard et al. (1976), erosion potential of soil is primarily a function of the size of soil particles, inter-particle cohesive forces, and velocity of transporting fluid (air or water). Erosion-resistant materials such as soil-gravel mixtures, gravel, riprap,

\footnotetext{
*Corresponding Author: Janarul Shaikh, Raman Global University, Bhubaneswar, Odisha, India; e-mail: jshaikh@cvrce.edu.in
} 
and geo-synthetic erosion control materials, may be utilized to help in reducing erosion (Gray \& Sotir, 1996). In addition to these, use of asphalt concrete, articulated block systems, construction and demolition wastes, and lightweight manufactured aggregates can also be used (Barnswell \& Dwyer, 2012).

Landreth et al. (1991) recommends a minimum cover soil thickness of $900 \mathrm{~mm}$ or greater for a few specific types of MLCSs such as evapotranspiration or capillary barrier cover system. The minimum thickness of surface layer is established based on consideration of rooting depth of surface vegetation, anticipated erosion rate, and construction tolerances (Øygarden et al., 1997). For shallow-rooted plants such as certain grasses, a $150 \mathrm{~mm}$ thick layer of soil usually provides adequate rooting depth (Zhan et al., 2007). Thus, the minimum thickness of a vegetated surface layer is generally $150 \mathrm{~mm}$ (USEPA, 1989). If plants with deeper roots are considered, thickness of topsoil should be increased to accommodate the excess root growth (Blight, 2009). The most common material used to construct the surface layer is locally available topsoil which contains adequate organic matter and plant nutrients (Hoor and Rowe, 2013). It helps to promote growth of vegetation (Khapre et al., 2017). Thus, previous researchers (Schnabel et al., 2012; Song et al., 2017) have had diverse opinions on the relation between erosion and infiltration in vegetated soils. Climatic factors affect the types of vegetation that grow on MLCS surface layers (Bonaparte et al., 2002). Climatic criteria for designing MLCSs may include quantity and seasonal distribution of precipitation, intensity and duration of specific storm events, seasonal temperature variations, depth of frost penetration, quantity of snow melt, wind speed and direction, solar radiation, and humidity (Jarvis et al., 2011). Heavy rainfall for a prolonged period leads to increase in rainwater infiltration and erosion of MLCS (Maqsoud et al., 2011). Drier climate results in shrinkage and desiccation cracks in MLCS surface layer (Landreth et al., 1991). Cracks may also develop due to the effects of freeze-thaw cycles in cold regions (Dune et al., 2011). Repeated cycles of wetting and drying can induce fatigue stress in the geomaterials, thereby deteriorating its performance (Nyhan et al., 1990). As a result, hydraulic conductivity may increase in surface layers because of cracks and root growth (Sinnathamby et al., 2014). The effect of climate change on functioning of MLCS has been rarely investigated from the purview of geotechnical engineering. Most of the existing studies solely discuss the influence of rainfall on surface erosion of vegetated cover soil (Shaikh et al., 2019b) without much emphasis on the infiltration happening simultaneously. Some studies (Gadi et al., 2017; Ghosh et al., 2019) attempted for understanding the infiltration rate through vegetated soils without considering the erosion. Limited studies (Zhang et al., 2014) attempted for evaluating the combined effects of infiltration and vegetation on rain induced erosion of surface soils of the MLCS.

This study attempts to address this issue by monitoring the infiltration of surface soils alongside the vegetation and erosion due to rainfall activity. The prime objective of the study is to access the temporal variation in erosion, infiltration, and vegetation characteristics of surface layer in a pilot Multilayered landfill cover system (MLCS) under natural and controlled rainfall simulation events.

\section{Materials and methods}

\subsection{Study area}

As understood from the above-mentioned literature, field monitoring programmes might solve such problems involving MLCS erosion. Hence for this study, a pilot MLCS was constructed in the backyard of the civil engineering department, Indian Institute of Technology Guwahati, India. Configuration and individual layer material of field model were selected in accordance with the

Table 1 Basic characteristics of soils used in the study

\begin{tabular}{|c|c|}
\hline Properties & $\begin{array}{l}\text { Clayey silt } \\
\text { (ML) }\end{array}$ \\
\hline Specific gravity & 2.65 \\
\hline Hygroscopic water content (\%) & 5 \\
\hline Saturated hydraulic conductivity $\left(\mathrm{m} . \mathrm{s}^{-1}\right)$ & $2.9 \mathrm{E}-8$ \\
\hline Specific surface area $\left(\mathrm{m}^{2} \cdot \mathrm{g}^{-1}\right)$ & 55 \\
\hline Linear shrinkage (\%) & 2 \\
\hline Free swell index (\%) & 10 \\
\hline \% mass of gravel (>4.75 mm) & 0 \\
\hline$\%$ mass of coarse sand $(2.0-4.75 \mathrm{~mm})$ & 17 \\
\hline$\%$ mass of medium sand $(0.425-2.0 \mathrm{~mm})$ & 16 \\
\hline$\%$ mass of fine sand $(0.075-0.425 \mathrm{~mm})$ & 16 \\
\hline$\%$ mass of silt $(0.002-0.075 \mathrm{~mm})$ & 19 \\
\hline$\%$ mass of clay $(<0.002 \mathrm{~mm})$ & 32 \\
\hline Liquid limit (\% mass) & 42 \\
\hline Plastic limit (\% mass) & 22 \\
\hline Shrinkage limit (\% mass) & 21 \\
\hline Plasticity index (\%) & 20 \\
\hline Optimum moisture content (\% mass) & 20 \\
\hline Maximum dry density $\left(\mathbf{g} \cdot \mathrm{cm}^{-3}\right)$ & 1.73 \\
\hline Soil pH value with water (at $28.5^{\circ} \mathrm{C}$ ) & 6.85 \\
\hline Organic content ( $\%$ mass) & 0.48 \\
\hline Cation exchange capacity (meq.100 g $\mathrm{g}^{-1}$ ) & 8 \\
\hline
\end{tabular}


recommendations of the United States Environmental Protection Agency (USEPA, 1989). Soils used for the MLCS model were locally collected from a nearby hill. The MLCS is made of the conventional layers: hydraulic barrier, drainage system, and surface protection layer along with various geosynthetic inclusions as additional barrier, drainage, and filter layers for superior performance. Locally available hill soil, reddish in colour, was selected for its use as a surface protection layer. Geotechnical characterization of this surface soil was evaluated using standard procedures in the ASTM guidelines (ASTM standard D422-63 (2007); ASTM standard D854 (2014); ASTM standard D5084 (2014); ASTM standard D4318 (2017)), and corresponding results are summarized in Table 1. It was low plastic clayey silt soil (ML according to the Unified soil classification system (ASTM standard D2487, 2017)). This soil would depict moderate infiltration and good resistance to erosion as understood from its plasticity and density characteristics. However, a detailed study would show an exact performance of the surface soil with growing vegetation.

\subsection{Experimental set-up}

The construction of the pilot cover system, filling up with materials, compacting every layer, erecting rainfall simulator, and installation of weather monitoring systems have been done with extreme care to avoid any kind of experimental errors. The coefficient of uniformity for $100 \mathrm{~mm}$ rainfall was found to be around 90\% (Shaikh et al., 2019a). About 8,000 kilograms of soils were used for preparing the setup. The usual recommendation of cover slope angle is 3 to $7^{\circ}$, however, to understand the worst probable performance a slope of $10^{\circ}$ is adopted in this study. The photograph of operational field set-up under simulated rainfall is presented in Fig. 1. The properties of rainfall simulator are in accordance with Shaikh et al. (2019b). A micro weather station equipped with rain gauge (ECRN 100 high-resolution double-spoon tipping bucket type rain gauge, Meter Group Inc. (2019a)) is installed in the vicinity of field pilot MLCS. The weather monitoring during the test period is summarized in Fig. 2. The rainfall simulation experiments are started after finishing the regular monsoon for understanding the maximum possible erosion scenario.

The surface area is categorized into small grids for quantifying spatial heterogeneity in vegetation growth, infiltration, and soil loss depth. The grid size was selected based on the initial measurements of vegetation and infiltration. Fig. 3. illustrates the layout of 81 locations, where the vegetation percentage, infiltration rate, and eroded depth of soil surface are measured on surface protection layer of MLCS. The vegetation density was measured in accordance with procedures detailed in Gadi et al. (2017) by collecting photographic images of vegetated surface with varying time and processing them with a freeware Image analysis program (Image-J) similar to methods followed by Shaikh et al. (2019b). The infiltration rate was attained through sequential measurements of $150 \mathrm{ml}$ Mini disk infiltrometer (MDI, Meter Group Inc. (2019b)) at every location as mentioned

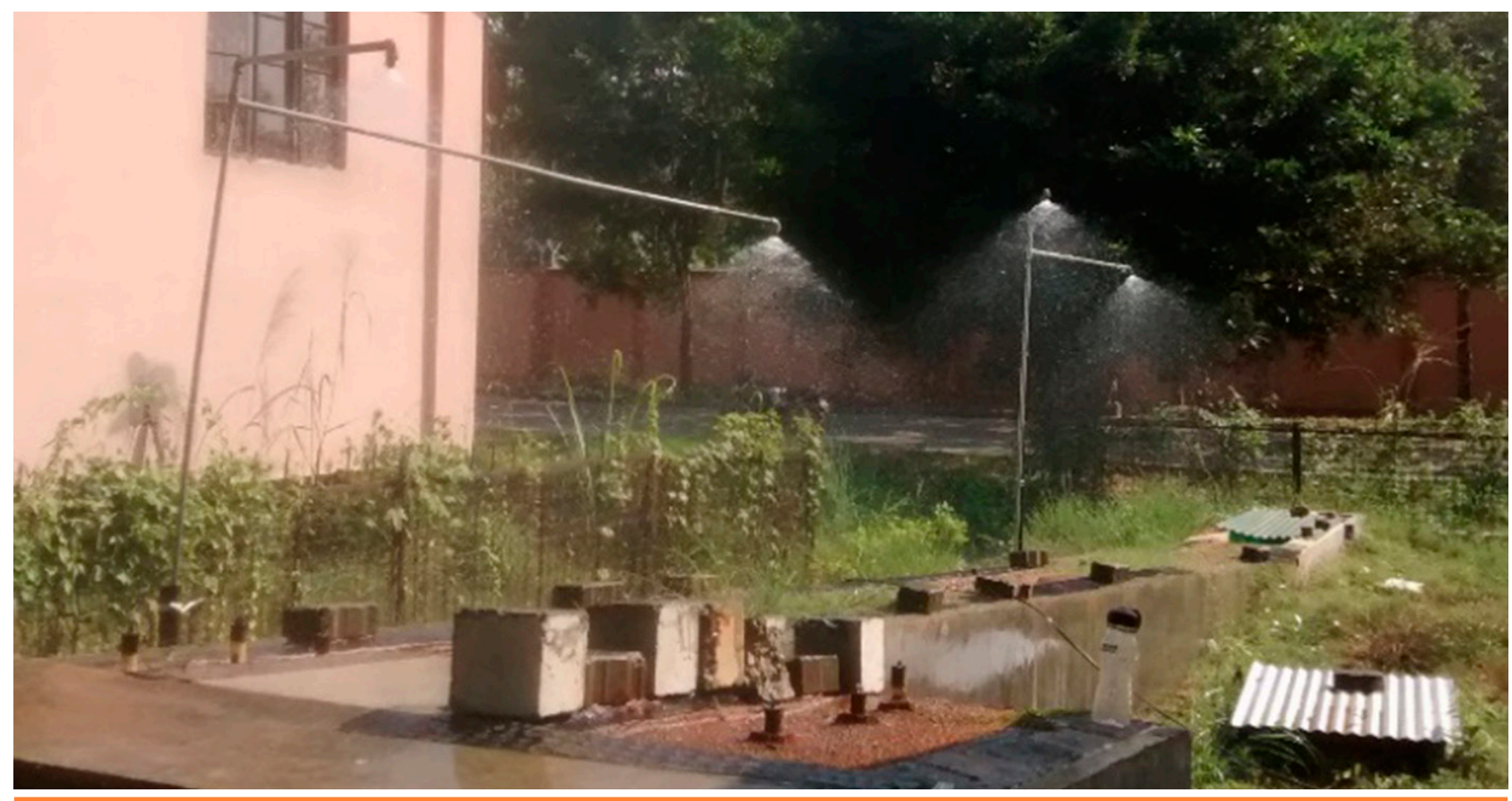

Figure 1

MLCS test setup during a rainfall simulation event 


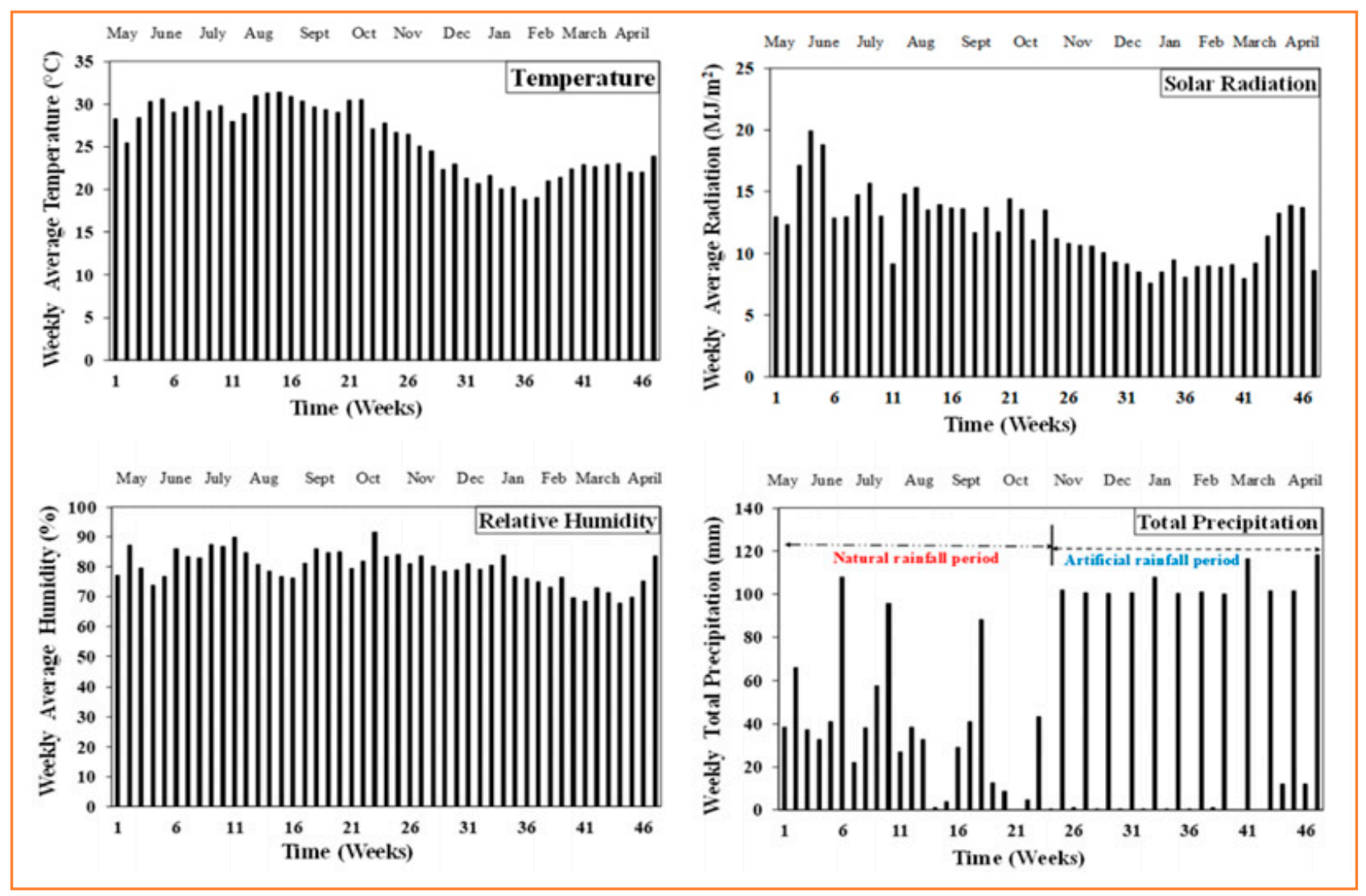

Figure 2 Weather monitoring during the test period monitored using ECRN 100

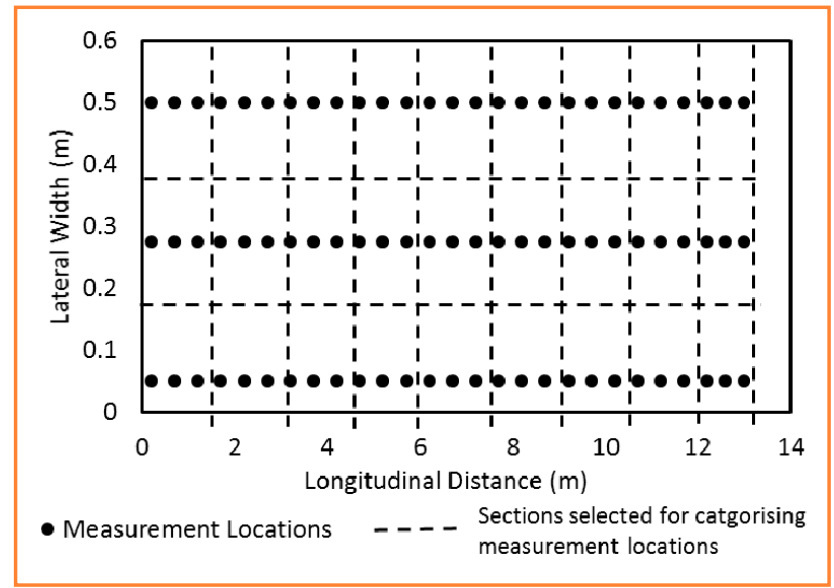

Figure 3 Schematic layout of measurement locations involved in evaluating surface layer

in the grid. Measurements were repeated in locations with desiccation cracks and increased grass cover, to account for all real field conditions as depicted in Fig. 4. Further, the varying depth of surface is measured using Vernier calipers at different points, to attain a spatial soil loss profile on temporal basis throughout the study period.

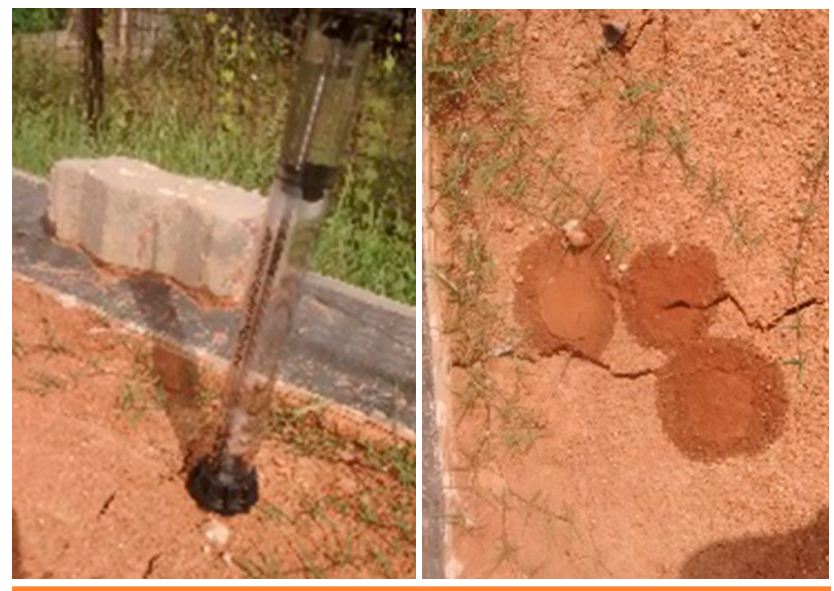

Figure 4 Repeated infiltration measurements around desiccation cracks on surface soil

\section{Results and discussion}

\subsection{Temporal variation of infiltration, vegetation, and erosion}

Fig. 5 depicts the contours describing the temporal variation of infiltration rate, vegetation density, and eroded depth of surface layer of the pilot MLCS under above-shown weather conditions. Though the study was conducted for one year and the data were evaluated 


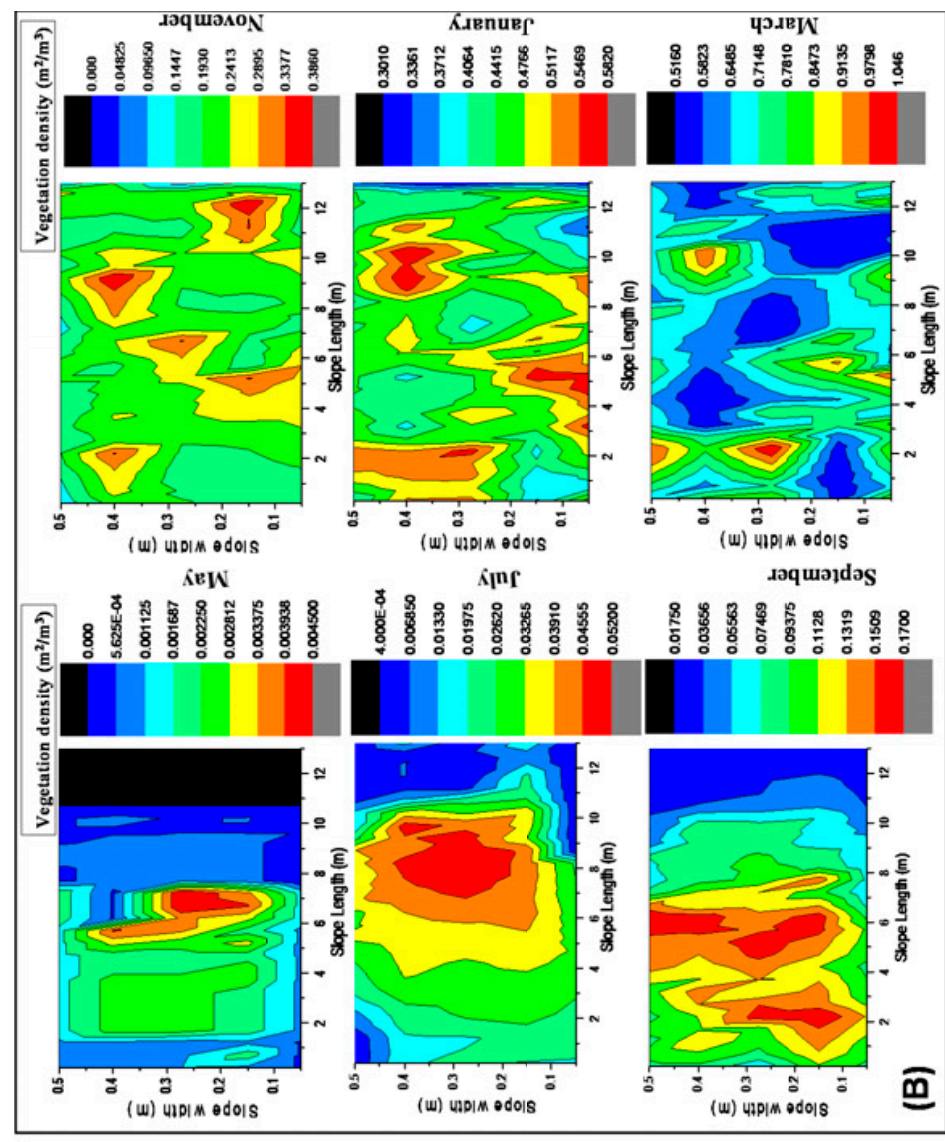

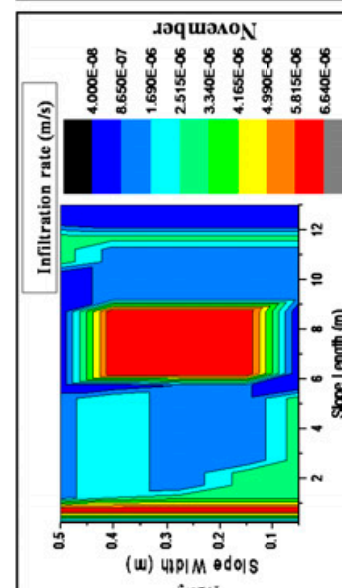

IEW

K.denue $\Gamma$ पวगBW

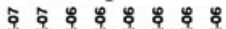

50 5 55888

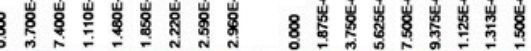
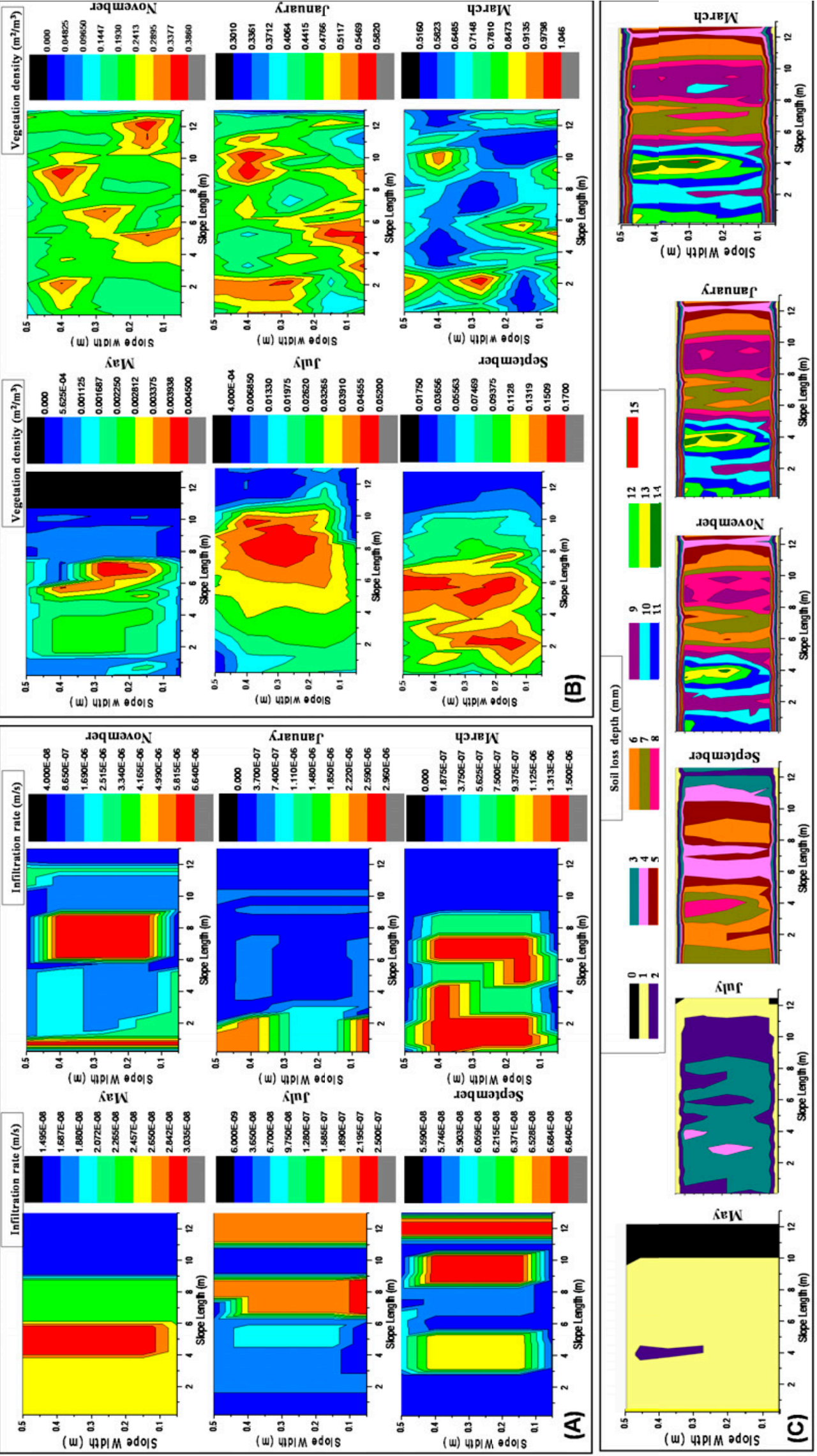

Figure 5

Temporal and spatial variation of infiltration, vegetation, and erosion 
on weekly basis, every two-month average results were considered in describing the contours to reduce the number of figures and have a representative picture. From the depicted results it can be observed that within the initial days the amount of infiltration, vegetation density, and eroded depth are relatively low indicating the effect of newly compacted surface layer. Similar results are observed by Shrestha et al. (2005); Bhave and Sreeja (2013); Adams and Smith (2014); Yamsani et al. (2017). The infiltration was observed to vary 6E-09 to $1.5 \mathrm{E}-$ 06 throughout the study period. The least infiltration was observed in months of July on the surface subjected to intense drying; such a behaviour is expected in general. The variation in infiltration rate for a particular period of time is about tenfold within the considered area of study. Greater degree of variation is observed with growing vegetation. Variation was also observed around the mild cracks generated during the dry spell. However, it was also noted that these mild cracks were found to be closed with high intensity rainfall simulations in the months of November and December. As a result, there is a decrease in corresponding infiltration rate for that particular time.

The eroded depth of soil was observed to vary from 0 to $15 \mathrm{~mm}$ within the considered study period accounting to about $5 \%$ of the surface soil thickness $(300 \mathrm{~mm}$ as suggested in USEPA (1989)). Significant amount of erosion was noted during the rainfall simulation period nearly $12 \mathrm{~mm}$, while during natural rainfall only about 6 $\mathrm{mm}$ of erosion was observed. The purpose of simulation experiments was to observe the worst possible behaviour of surface soil layer. Fig. 2 depicts only 3 weeks of about $100 \mathrm{~mm}$ cumulative precipitation during the natural monsoon, and there were only couple of cloud burst events accounting to about $70 \mathrm{~mm}$ rainfall during the natural cycle. Consecutive simulation of 12 cloud burst events has generated about $12 \mathrm{~mm}$ depth of soil loss. In this $12 \mathrm{~mm}$ of erosion depth, most of it was observed in the early months of July to November. Further, no significant variations in depth of erosion were noticed from months of November to March indicating nearly stable behaviour. Increased vegetation density and reduced climatic variations might be attributed for this stable behaviour which was similar to the observation made by Shaikh et al. (2019b).

\subsection{Spatial variation of infiltration, vegetation, and erosion}

Early results in Fig. 5, indicate that the infiltration increased with increasing the length of the slope. Infiltration in the toe regions was relatively high owing to the loose soil structure formed as a result of erosion from crest of the slope. In contrast, the vegetation density is relatively low towards the toe region. Thus, the interception (water retention on the plant leaves) was small. Hence, bigger proportion was distributed between infiltration and surface runoff. This significantly influences the variation in runoff as well as the settlement of eroded soil mass. The settled soil mass near the toe region even influenced the eroded depth to indicate a relatively lower value. However, all these variations are evident in initial stages of study, and in later stages, a uniform variation in observed parameters was noted. This could be likely due to the controlled rainfall condition in simulation experiments, relatively uniform weather conditions, and due to increased stability because of enhanced vegetation density in months of November to March. The all-time biggest soil loss depth was seen at the slope length of $4 \mathrm{~m}$. This is likely due to lack of uniformity in compacting the soil of this region or the presence of some foreign loose matter in the soil of this region. The observed low soil loss towards the toe region is likely due to runoff sedimentation.

\subsection{Influence of infiltration on erosion of vegetated soil}

In general, the runoff and consecutive erosion are observed to be low when infiltration is high. However, the surface dryness was noted to increase infiltration and erosion in the months of July to November due to increased temperatures while the vegetation density was relatively low. And in the later stages of the study, as the vegetation density increased, the water holding capacity of surface soil was observed to increase. Hence, the average infiltration rate in both wet and dry weeks was observed to increase. Such findings were reported in Gadi et al. (2017) while studying hydraulic conductivity in green infrastructures. During this stage, the erosion rate is relatively low in comparison to early stages of study. In summary, this indicates the strong interplay between the infiltration and erosion behaviour of vegetated soil. For better understanding the relation between infiltration and erosion behaviour of vegetated soil, an integrated model that considers continuous changes of these parameters and resulting degradation needs to be developed. Such a study would bring a preliminary inference in developing effective soil loss models for surface soils used in MLCSs.

\section{Conclusions}

This article deals with the field evaluation of surface soil layer of a pilot MLCS in terms of its erosion and infiltration rate under the influence of natural and simulated rainfall for a period of a year. The study evidently presented the diverse reasons behind contrasting behaviour of erosion at higher rates of infiltration in vegetated and partially vegetated soil. Antecedent moisture contents have 
greater influence on erosion and infiltration behaviour of surface soils. The rate of infiltration was observed to increase during days of no rainfall due to the formation of surface desiccation cracks and low in-situ water contents. Further, the infiltration was found to decrease with partial closure of desiccation cracks and increase in antecedent water contents owing to high intensity rainfall during simulated rainfall study. The high soil losses due to erosion during simulated rainfall events decreased significantly, as the vegetation increased. Vegetation was found to have significant effect on reducing the soil loss depth of surface soil layer of MLCSs. The study indicates the need of bioengineering for protecting the surface layer of MLCSs.

\section{Acknowledgments}

The authors would like to thankfully acknowledge the board of research in nuclear sciences (BRNS), Department of Atomic Energy (DAE), India for the financial support provided for the work reported in this paper vide project no. 2013/36/06-BRNS.

\section{References}

Adams, M. P., \& Smith, P. L. (2014). A systematic approach to model the influence of the type and density of vegetation cover on urban heat using remote sensing. Landscape and Urban Planning, 132, 47-54.

Anderson, C. E., \& Stormont, J. C. (1997). Prediction of longterm erosion from landfill covers in the southwest (No. CONF970208-PROC). USDOE, Washington, DC (United States). ASTM standard D2487 (2017). Standard practice for classification of soils for engineering purposes (unified soil classification system).

ASTM standard D422-63 (2007). Standard test method for particle-size analysis of soils.

ASTM standard D4318 (2017). Standard test methods for liquid limit, plastic limit, and plasticity index of soils.

ASTM standard D5084 (2014). Standard test methods for measurement of hydraulic conductivity of saturated porous materials using a flexible wall permeameter.

ASTM standard D854 (2014). Standard test method for specific gravity of soil solids by water pycnometer.

Barnswell, K. D., \& Dwyer, D. F. (2012). Two-year performance by evapotranspiration covers for municipal solid waste landfills in northwest Ohio. Waste Management, 32(12), 2336-2341.

Bhave, S., \& Sreeja, P. (2013). Influence of initial soil condition on infiltration characteristics determined using a disk infiltrometer. ISH Journal of Hydraulic Engineering, 19(3), 291-296.

Blight, G. (2009). Solar heating of the soil and evaporation from a soil surface. Géotechnique, 59(4), 355-363.

Bonaparte, R., Daniel, D. E., \& Koerner, R. M. (2002). Assessment and Recommendations for Improving the Performance of Waste Containment Systems. United States Environmental Protection Agency, Office of Research and Development, National Risk Management Research Laboratory.
Gadi, V. K., Tang, Y. R., Das, A., Monga, C., Garg, A., Berretta, C. \& Sahoo, L. (2017). Spatial and temporal variation of hydraulic conductivity and vegetation growth in green infrastructures using infiltrometer and visual technique. Catena, 155, 20-29.

Ghosh, B., Pekkat, S., \& Yamsani, S. K. (2019). Evaluation of infiltrometers and permeameters for measuring hydraulic conductivity. Advances in Civil Engineering Materials, 8(1).

Gray, D. H., \& Sotir, R. B. (1996). Biotechnical and Soil Bioengineering Slope Stabilization: A Practical Guide for Erosion Control. New York: John Wiley \& Sons.

Gross, B. A., Bonaparte, R., \& Giroud, J. P. (2002). Waste containment systems: problems and lessons learned (Appendix $F$ in Assessment and Recommendations for Optimal Performance of Waste Containment Systems). US Environmental Protection Agency, National Risk Management Research Laboratory.

Hoor, A., \& Rowe, R. K. (2013). Potential for desiccation of geosynthetic clay liners used in barrier systems. Journal of Geotechnical and Geoenvironmental Engineering, 139(10), 1648-1664.

Jarvis, A., Ramirez, J., Bonilla-Findji, O., \& Zapata, E. (2011). Impacts of climate change on crop production in Latin America. Crop adaptation to climate change (pp. 44-56).

Khapre, A., Kumar, S., \& Rajasekaran, C. (2017). Phytocapping: an alternate cover option for municipal solid waste landfills. Environmental Technology, Taylor \& Francis, 6, 1-8.

Koerner, R. M., \& Daniel, D. E. (1997). Final covers for solid waste landfills and abandoned dumps. Thomas Telford, ASCE Press.

Landreth, R. E., Daniel, D. E., Koerner, R. M., Schroeder, P. R., \& Richardson, G. N. (1991). Design and construction of RCRACERCLA final covers. Seminar Peblication.

Maqsoud, A., Bussière, B., Aubertin, M., Chouteau, M., \& Mbonimpa, M. (2011). Field investigation of a suction break designed to control slope-induced desaturation in an oxygen barrier. Canadian Geotechnical Journal, 48(1), 53-71.

Meter Group Inc. (2019a). Microclimate monitoring system for measuring various weather parameters. Operator's User Manual. Meter Group Inc., Pullman, WA. Retrieved December 30, 2020 from https://www.metergroup.com/environment/ products/ecrn-100/

Meter Group Inc. (2019b). Mini disk infiltrometer. Operator's User Manual. Meter Group Inc., Pullman, WA 99163. Retrieved December 30, 2020 from https://www.metergroup.com/ environment/products/mini-disk-infiltrometer/

Morris, C. E., \& Stormont, J. C. (1998). Evaluation of numerical simulations of capillary barrier field tests. Geotechnical and Geological Engineering, 16(3), 201-213.

Nyhan, J. W. (2005). A Seven-Year Water Balance Study of an Evapotranspiration Landfill Cover Varying in Slope for Semiarid Regions. Vadose Zone Journal, 4(3), 466.

Nyhan, J. W., Hakonson, T. E., \& Drennon, B. J. (1990). A water balance study of two landfill cover designs for semiarid regions. Journal of Environmental Quality, 19(2), 281-288.

Øygarden, L., Kværner, J., \& Jenssen, P. D. (1997). Soil erosion via preferential flow to drainage systems in clay soils. Geoderma, 76(1-2), 65-86.

Schnabel, W. E., Munk, J., Lee, W. J., \& Barnes, D. L. (2012). Fouryear performance evaluation of a pilot-scale evapotranspiration 
landfill cover in Southcentral Alaska. Cold Regions Science and Technology, 82, 1-7.

Shaikh, J., Bordoloi, S., Yamsani, S. K., Sekharan, S., Rakesh, R. R., \& Sarmah, A. K. (2019a). Long-term hydraulic performance of landfill cover system in extreme humid region: Field monitoring and numerical approach. Science of the Total Environ., 688, 409-423.

Shaikh, J., Yamsani, S. K., Bora, M. J., Sekharan, S., Rakesh, R. R., Mungale, A., \& Bordoloi, S. (2019b). Impact assessment of vegetation growth on soil erosion of a landfill cover surface. Acta Horticulturae et Regiotecturae, 22(2), 75-79.

Shaikh, J., Bordoloi, S., Leung, A. K., Yamsani, S. K., Sekharan, S., \& Rakesh, R. R. (2021). Seepage characteristics of threelayered landfill cover system constituting fly-ash under extreme ponding condition. Science of the Total Environ., 758, 143683.

Sherard, J. L., Dunnigan, L. P., \& Decker, R. S. (1976). Identification and Nature of Dispersive Soils. Journal of the Geotechnical Engineering Division, 102(GT4), 287-301.

Shrestha, G., Stahl, P. D., \& Ingram, L. (2005). Influence of reclamation management practices on soil bulk density and infiltration rates on surface coal mine lands in Wyoming. National Meeting of the American Society of Mining and Reclamation (pp. 1042-1056), Lexington, KY: ASMR.

Sinnathamby, G., Pasky, A., Phillips, D. H. H., \& Sivakumar, V. (2014). Landfill cap models under simulated climate change precipitation: impacts of cracks and root growth. Géotechnique, 64(2), 95-107.
Song, L., Li, J. H., Zhou, T., \& Fredlund, D. G. (2017). Experimental study on unsaturated hydraulic properties of vegetated soil. Ecological Engineering, 103, 207-216.

Swope, G. L. (1975). Revegetation of Landfill Cover Sites. Pennsylvania State University, State Park, PA.

USEPA. (1989). Requirements for hazardous waste landfill design, construction, and closure (pp. 1-127. Seminar publication, Report No. 625/4-89/022). United States Environmental Protection Agency.

Xue, Q., Chen, Y. J., \& Liu, L. (2016). Erosion characteristics of ecological sludge evapotranspiration cover slopes for landfill closure. Environmental Earth Sciences, 75(5), 419.

Yamsani, S. K., Kumar, S., Sekharan, S., \& Ranjan, R. R. (2017). Determination of soil erosion index for surface soils of landfill covers. Environmental Geotechnics, 6(6), 373-380.

Zhan, T. L., Ng, C. W., \& Fredlund, D. G. (2007). Field study of rainfall infiltration into a grassed unsaturated expansive soil slope. Canadian Geotechnical Journal, 44(4), 392-408.

Zhang, X., Yu, G. Q., Li, Z. B., \& Li, P. (2014). Experimental study on slope runoff, erosion and sediment under different vegetation types. Water resources management, 28(9), 2415-2433. 